\title{
cGMP-binding Prepares PKG for Substrate Binding by Disclosing the C-terminal Domain
}

\author{
Vera Alverdi ${ }^{1,2}$, Hortense Mazon ${ }^{1}$, Cees Versluis ${ }^{1}$, Wieger Hemrika ${ }^{3}$, \\ Gennaro Esposito ${ }^{2}$, Robert van den Heuvel ${ }^{1}$, Arjen Scholten ${ }^{1}$ \\ and Albert J. R. Heck ${ }^{1 *}$
}

\author{
${ }^{1}$ Department of Biomolecular \\ Mass Spectrometry, Bijvoet \\ Center for Biomolecular \\ Research and Utrecht Institute \\ for Pharmaceutical Sciences, \\ Utrecht University, \\ Sorbonnelaan 16, 3584 CA \\ Utrecht, The Netherlands \\ ${ }^{2}$ Department of Biomedical \\ and Biotechnological Science, \\ Udine University, Udine, Italy \\ ${ }^{3}$ Department of Protein \\ Crystallography, Bijvoet Center \\ for Biomolecular Research, \\ Utrecht University, Utrecht, \\ The Netherlands
}

Received 17 July 2007; received in revised form 23 October 2007; accepted 15 November 2007 Available online 22 November 2007

Edited by S. Radford

\begin{abstract}
Type I cyclic guanosine $3^{\prime}, 5^{\prime}$-monophosphate (cGMP)-dependent protein kinase $(\mathrm{PKG})$ is involved in the nitric oxide/cGMP signaling pathway. PKG has been identified in many different species, ranging from unicelõlular organisms to mammals. The enzyme serves as one of the major receptor proteins for intracellular cGMP and controls a variety of cellular responses, ranging from smooth-muscle relaxation to neuronal synaptic plasticity. In the absence of a crystal structure, the three-dimensional structure of the homodimeric 152-kDa kinase PKG is unknown; however, there is evidence that the kinase adopts a distinct cGMP-dependent active conformation when compared to the inactive conformation. We performed mass-spectrometry-based hydrogen/deuterium exchange experiments to obtain detailed information on the structural changes in PKG I $\alpha$ induced by cGMP activation. Site-specific exchange measurements confirmed that the autoinhibitory domain and the hinge region become more solvent exposed, whereas the CGMP-binding domains become more protected in holo-PKG (dimeric PKG saturated with four cGMP molecules bound). More surprisingly, our data revealed a specific disclosure of the substrate-binding region of holo-PKG, shedding new light into the kinase-activation process of PKG.
\end{abstract}

(C) 2007 Elsevier Ltd. All rights reserved.

Keywords: cGMP-dependent protein kinase I $\alpha$; PKG; kinase activation; ion mobility; hydrogen/deuterium exchange mass spectrometry
*Corresponding author. E-mail address: A.J.R.Heck@uu.nl. Present addresses: R. van den Heuvel, N.V. Organon, Biotech Analytical Development, 5340 BH Oss, The Netherlands; A. Scholten, Cellzome, Analytical Sciences, 69117 Heidelberg, Germany.

Abbreviations used: cGMP, cyclic guanosine $3^{\prime}, 5^{\prime}-$ monophosphate; PKG, cGMP-dependent protein kinase; holo-PKG, dimeric PKG saturated with four cGMP molecules bound; PKA, cAMP-dependent protein kinase; $\mathrm{H} / \mathrm{D}$, hydrogen/deuterium; MALDI-MS, matrix-assisted laser desorption ionization mass spectrometry; apo-PKG, dimeric PKG without cGMP; HDX-MS, H/D exchange mass spectrometry; ESI-MS, electrospray ionization mass spectrometry; EDTA, ethylenediaminetetraacetic acid; TOF, time of flight.

\section{Introduction}

Cyclic guanosine $3^{\prime}, 5^{\prime}$-monophosphate (cGMP)dependent protein kinases (PKGs) are the main downstream effectors of second-messenger cGMP. They are activated upon intracellular generation of cGMP by two main types of guanylate cyclases: soluble and membrane associated. ${ }^{1}$ The first acts downstream of nitric oxide, while the latter is activated through extracellular binding of natriuretic peptides. Both signals mediate a variety of important physiological processes through cGMP and its kinases. cGMP-dependent kinases are implicated in the regulation of, among others, smoothmuscle relaxation ${ }^{2}$ and platelet function.,

cGMP kinases and their cAMP-dependent protein kinase (PKA) counterparts serve as the major intra- 
cellular mediators of cyclic nucleotide signaling pathways. Both kinases are allosterically regulated proteins, and much of our current understanding of protein kinases' structure, function and regulation is primarily based on studies of PKA and, to a lesser extent, PKG. PKA is an $\mathrm{R}_{2} \mathrm{C}_{2}$ hetero-tetramer whereby the holo-enzyme dissociates into two catalytic domains (2C) and a dimer of the regulatory subunits $\left(R_{2}\right)$ upon stimulation by cAMP. For PKA, detailed pictures of all the processes from regulation to enzymatic turnover exist. ${ }^{5,6}$ Several crystal structures of the catalytic subunit of PKA in the presence of nucleotide, substrate and inhibitors, ${ }^{7,8}$ as well as the apo-enzyme ${ }^{9}$ and the holo-enzyme, ${ }^{10}$ are available. These structures probably provide the best examples of how a kinase recognizes its substrates, as well as inhibitors, and also how the enzyme moves through catalysis. To complement crystallographic structures, fluorescence anisotropy, ${ }^{11,12} \mathrm{NMR}^{13,14}$ and hydrogen/deuterium (H/D) exchange coupled with mass spectrometry ${ }^{15-20}$ have been used to probe the dynamic behavior of PKA. Compared to PKA, much less information is available for PKG, for which, for instance, no crystal structures have yet been reported. For PKG, the mammalian genome encodes a type I kinase ${ }^{21,22}$ and a type II kinase. $^{23,24}$ Mammalian type I PKGs are homodimeric cytosolic proteins containing two identical polypeptides of $\sim 76 \mathrm{kDa}$. PKG subunits contain a regulatory domain and a catalytic domain. Alternative mRNA splicing produces the type I $\alpha$ PKG and a type I $\beta$ PKG, which only differ in their first $\sim 70-100$ amino-terminal residues. ${ }^{25,26}$ Here we focus on full-length bovine PKG I $\alpha$, which harbors several functional domains on a single polypeptide chain (see Fig. 1). The primary sequence of the subunits has been divided into three separate segments: an amino-terminal, a regulatory segment and a catalytic segment. ${ }^{27}$ The amino-terminal segment contains a dimerization site, an autoinhibitory motif and several autophosphorylation sites. A hinge region connects the amino-terminal site with the two intandem cGMP-binding pockets. The $\mathrm{C}$-terminal part of the protein harbors the catalytic domain, which consists of a MgATP-binding pocket and the substrate-binding site.

The two homologous cyclic-nucleotide-binding regions of PKG ( 110 amino acids each) are arranged in tandem in the amino-terminal moiety. They preferentially bind cGMP over cAMP with a $>100-$ fold selectivity, whereas the cyclic-nucleotide-binding sites of PKA preferentially bind cAMP over cGMP with a >50-fold selectivity. The cyclic nucleo- tide specificity of PKG for cGMP is largely determined by the presence of an invariant threonine corresponding to an alanine in the cAMP-binding site of PKA. ${ }^{28,29}$ The reported $K_{\mathrm{d}}$ values of the two cGMP-binding sites of PKG I $\alpha$ are all in the nanomolar range at $30^{\circ} \mathrm{C} .{ }^{30}$

The catalytic domain of a protein kinase transfers the ATP $\gamma$-phosphate onto a serine, threonine or tyrosine residue of the substrate. The C-terminal substrate-binding domains of PKG and PKA are thought to be very important to substrate specificity. Although PKG and PKA share a similar substrate phosphorylation consensus sequence, they phosphorylate different substrates in vivo. ${ }^{31,32}$ There are many notable differences in the C-terminal substrate-binding domains of PKG and PKA that likely cause the specificity differences.

Most serine/threonine-specific or tyrosine-specific protein kinases are activated by allosteric ligand binding (e.g., cAMP, cGMP, calcium, insulin and epidermal growth factor), but the molecular mechanism involved in such activation is not fully understood in most cases. For PKA, the binding of cAMP to the inactive $\mathrm{R}_{2} \mathrm{C}_{2}$ hetero-tetramer induces dissociation, which liberates the catalytic subunits from the regulatory subunits. ${ }^{5}$ In contrast, in PKG, the catalytic and regulatory domains reside on a single polypeptide chain, and a similar dissociation cannot occur. In the absence of cGMP, PKG is maintained in a basal state by the binding of a pseudosubstrate site within the regulatory domain to the catalytic domain, a process described as autoinhibition. ${ }^{33,34}$ The relative activity in this basal state was established for PKG I $\alpha$ to be $\sim 10 \%$ of the maximal activity in vitro. ${ }^{35}$ In addition, it was reported that autophosphorylation of PKG in the regulatory domain increases basal activity. ${ }^{36}$ When intracellular cyclic nucleotide levels rise, the kinase becomes active. Hence, heterophosphorylation of target proteins can occur. The exact molecular mechanism of the cGMP stimulus is still unknown. Evidence suggests that activation of PKG, either by cGMP binding or by autophosphorylation, is associated with a conformational change that releases the autoinhibitory domain from the catalytic site, thereby reducing the efficiency of the pseudosubstrate-site competition for substrate binding. ${ }^{37,38}$ A maximally active kinase is obtained when all four cGMP-binding sites of the dimeric kinase are occupied. Activation of PKG by cGMP is associated with an expansion of the protein structure, as revealed by small-angle X-ray scattering. ${ }^{39,40}$ Fourier transform infrared spectroscopy data suggest

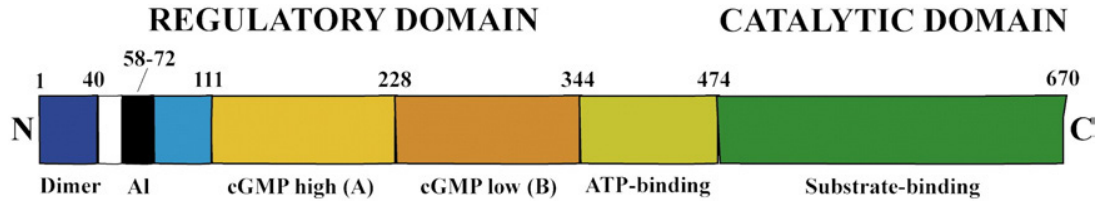

Fig. 1. Schematic representation of the functional domain structure of one monomer of dimeric PKG I $\alpha$. At the N-terminus, the dimerization domain is depicted. AI=the autoinhibition domain; cGMP high (called A)=high-affinity binding domain for cGMP; cGMP low (called B)=low-affinity binding domain for cGMP. 
that the conformational change induced by cGMP binding is primarily due to a topographical movement of PKG structural domains rather than the secondary structural changes within one or more of the individual domains. ${ }^{39}$ Studies of cGMP-induced changes by combination of ion-exchange chromatography, gel-filtration chromatography, native polyacrylamide gel electrophoresis and partial proteolysis showed that the apparent elongation of the protein is associated with an increase in net surface charge. ${ }^{41}$ Here, we investigated the implications of cGMP binding on the structure and conformation of bovine PKG I $\alpha$ by measuring global $\mathrm{H} / \mathrm{D}$ exchange on the intact $152-\mathrm{kDa}$ apo-protein and holo-protein with native mass spectrometry, ${ }^{42}$ and by measuring more detailed localized H/D exchange events on the peptides formed by pepsin and type XIII digestions with matrix-assisted laser desorption ionization mass spectrometry (MALDIMS). ${ }^{43,44}$ Additionally, we performed ion mobility measurements on the intact apo-PKG (dimeric PKG without cGMP) and holo-PKG (dimeric PKG saturated with four cGMP molecules bound) to investigate whether the cGMP-induced kinase structural expansion of PKG can also be observed in the gas phase. We propose a more detailed structural model describing the conformational changes induced in PKG upon cGMP binding, which includes a thus far unreported opening of the substrate-binding region that is consistent with the involvement of this region in the kinase-activation process.

\section{Results}

H/D exchange mass spectrometry (HDX-MS) is nowadays a well-established method in structural biology that is used to study conformational changes and protein folding. ${ }^{45-49}$ In HDX-MS, electrospray ionization mass spectrometry (ESI-MS) is the most popular method used to produce ions from deuterated samples for subsequent mass spectrometric analysis, but, more recently, MALDI-MS has also been used for the same purpose. ${ }^{50}$ With MALDI-MS, it is possible to avoid time-consuming HPLC separation of peptides, thereby reducing backexchange. ${ }^{51}$ In addition, the relatively simple data acquisition makes HDX-MALDI-MS a straightforward method for studying in detail protein-ligand interactions ${ }^{52}$ and protein-protein interfaces. ${ }^{53,54}$

We used three different technical approaches to obtaining information about conformational changes induced in PKG I $\alpha$ by the binding of cGMP, (a) deuterium incorporation into the intact protein measured by native ESI-MS, (b) gas-phase ion mobility and (c) deuterium incorporation mapping protein segments obtained by rapid proteolysis after labeling, coupled to MALDI-MS.

\section{Global H/D exchange of PKG confirms the conformational opening of the activated enzyme}

Figure 2a shows the mass spectrum of apo-PKG electrosprayed from an aqueous 200-mM ammonium acetate solution at a dimer concentration of
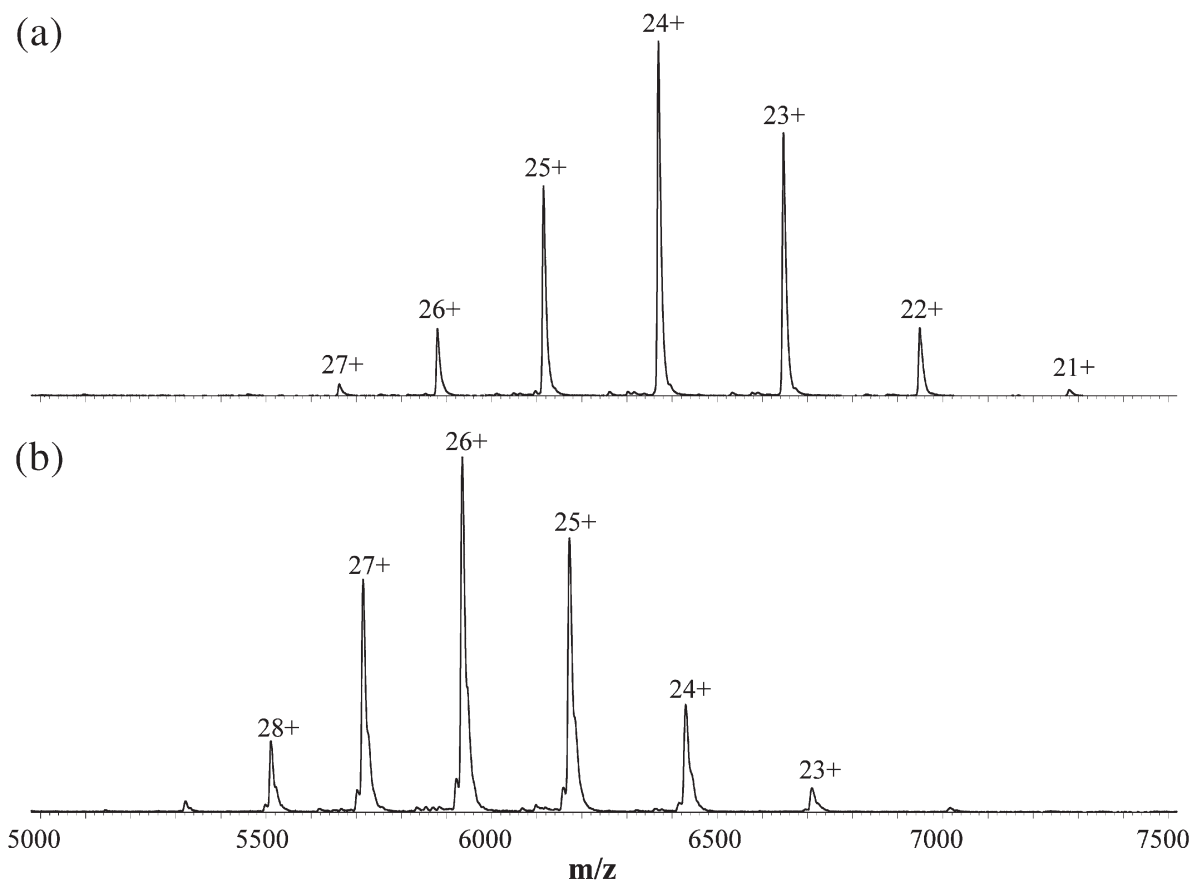

Fig. 2. Native mass spectra of intact apo-PKG (a) and cGMP-saturated holo-PKG (b). The mass spectra display charge state distributions from which the mass could be derived. The charge state distribution in (a) originates exclusively from $(\mathrm{PKG})_{2}$, whereas in (b), the charge state distribution originates from PKG with four cGMP molecules bound (i.e., $\mathrm{PKG}_{2}$ $\left.[\mathrm{cGMP}]_{4}\right)$. Surprisingly, the charge state envelope of holo-PKG is shifted towards a higher charge, indicating that more residues have become accessible for protonation during the ESI process, indicative of a conformational change. 
$\sim 2.5 \mu \mathrm{M}$. The charge state envelope of the dimer was centered around an $m / z$ value of 6400 . The theoretical average mass of the dimeric PKG, calculated from the sequence without the expression of methionine, with acetylated N-termini and without any additional cGMP or phosphorylation residues is $152,657 \mathrm{Da}$, whereas the experimental mass is $152,896 \pm 9.2 \mathrm{Da}$. The latter value indicates the presence of, on average, two phosphorylated sites in the apo-protein and a certain percentage of solvation that is commonly observed while measuring large proteins under native conditions by mass spectrometry.

Using liquid chromatography mass spectrometry / mass spectrometry, we tested the phosphorylation status on a proteolytic digest of apo-PKG. This revealed that Thr516 within the activation loop is stoichiometrically phosphorylated. As known, this phosphorylation site is essential for the catalytic activity of this kinase.

The second phosphorylated site is supposed to be one of the PKG autophosphorylated sites identified in the N-terminal region of the protein (Ser26, Ser44, Ser50, Thr58, Ser72, Thr84 and, with minor phosphorylation, Ser1 and Ser64). Supplementary Table 1 reports the data corresponding to the site-specific detection of protein phosphorylation for PKG $\mathrm{I} \alpha{ }^{36,55}$ Figure $2 \mathrm{~b}$ shows the mass spectrum of PKG in the presence of cGMP in a concentration ratio of 1:5 (PKG:cGMP). The charge state distribution centered around an $m / z$ value of 5700 corresponded to dimeric PKG with four cGMP molecules bound $\left(\mathrm{PKG}_{2}\left[\mathrm{cGMP}_{4}\right)\right.$. Interestingly, in holo-PKG, we observed a shift of the charge state distribution to higher values, which features a mass spectrometry pattern that is often attributed to an opening of the protein structure, making additional residues accessible to protonation during the ESI process. This shift in charge distribution between apo-PKG and holo-PKG is in line with previously reported observations. $^{56,57}$

In order to probe the global conformational changes in PKG that occur upon binding of cGMP, we used a differential real-time HDX-MS approach on the intact inactive and active dimers. In this approach, the exchange of both backbone and side-chain hydrogen atoms is monitored in real time. In two separate experiments, solutions of apo-PKG and holo-PKG (i.e., incubated for $5 \mathrm{~min}$ with cGMP in ratios of 1:5 and 1:10) were diluted 10 times in a 200-mM ammonium acetate deuterated solution and immediately analyzed by native mass spectrometry. In Fig. 3, the global deuterium exchange kinetics of apo-PKG and holo-PKG are depicted. A significant difference in deuterium incorporation is readily seen between apoPKG and holo-PKG over the whole time window studied. At $20 \mathrm{~min}$, apo-PKG exchanged $75 \%$ of the labile hydrogen content (1596 out of 2138 hydrogen atoms), whereas for holo-PKG, the exchange progressed up to $83 \%$. The significantly higher H/D exchange in holo-PKG-an increase of $190 \pm 10$ deuterium-was reproducible and in agreement with the opening of the PKG structure in the presence

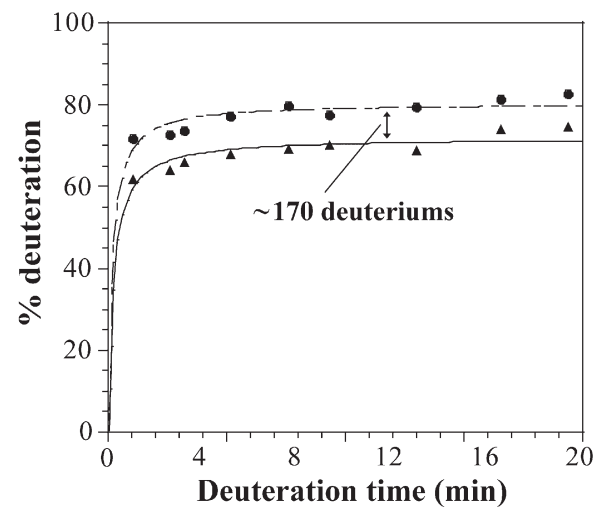

Fig. 3. Global H/D exchange behavior of apo-PKG and holo-PKG determined by native mass spectrometry. The graph shows the percentage (with standard deviations) of exchanged hydrogen atoms (i.e., incorporated deuterium molecules) as a function of time for apo-PKG $(\boldsymbol{\Delta})$ and holo-PKG $(\mathbf{O})$. Over the whole time window, holo-PKG had approximately 170 more hydrogen atoms exchanged than apo-PKG. In global exchange, both amide and side-chain hydrogen atoms may be exchanged.

of cGMP. ${ }^{38}$ Moreover, the result is consistent with the observed higher charging of holo-PKG compared to apo-PKG described above.

\section{Ion mobility reveals an opening of the structure in holo-PKG}

In recent years, ion mobility, in combination with mass spectrometry, has become a novel tool for probing the structural and conformational properties of biomolecules in the gas phase. ${ }^{58,59}$ Ion mobility separation is based on spatial separation of gas-phase ion species due to differences in their mobility through a buffer gas. The time used by the ions to traverse the drift tube is called drift time. It has been recently shown by ion mobility mass spectrometry that some of the structural aspects of protein structures may be retained and thus probed in the gas phase. ${ }^{60,61}$ This prompted us to analyze the gas-phase ion mobility of active and inactive PKG, using a Synapt Q-Tof instrument. The samples were prepared using the same protocol as for the native mass spectrometry measurements described above. Figure 4 shows the ion mobility data for both apo-PKG and holo-PKG that revealed small but significant and reproducible differences. The 2D maps show the drift times of every charge state of apo-PKG (panel a) and holo-PKG (panel b). This is further illustrated in Fig. $4 c$, where the drift-time distributions of $[M+27]^{27+}$ of apo-PKG and holoPKG are overlaid. The mean ion mobility drift times for each of the detected charge states of apo-PKG and holo-PKG are plotted in Fig. 4d. For each detected charge state, holo-PKG exhibited longer drift times than apo-PKG. The drift time of an ion in the mobility device is dependent on many parameters, including mass and charge, but also conformation. For the same charge state, and nearly identical mass, the difference in drift time most 
(a)

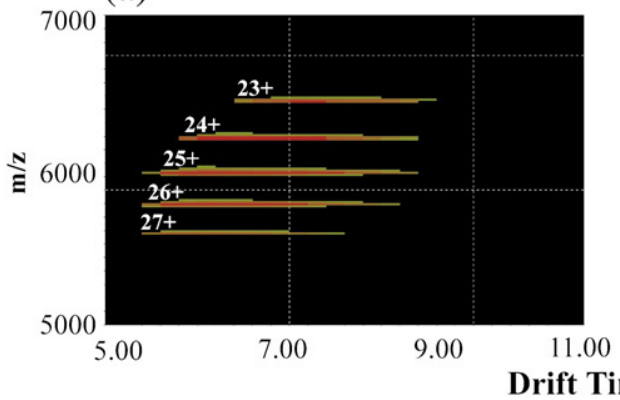

(c)

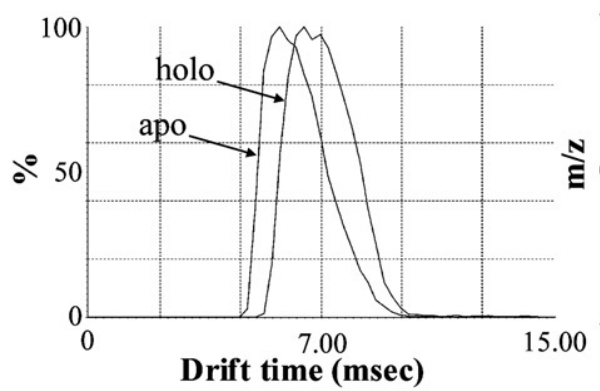

(b)

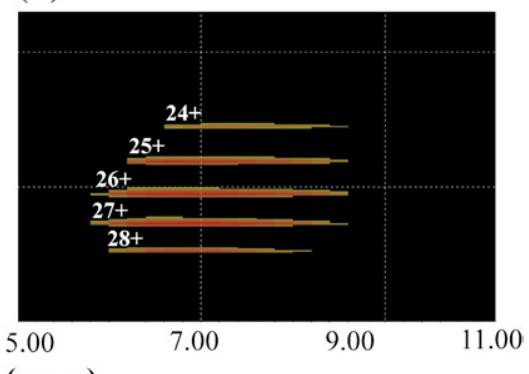

(d)

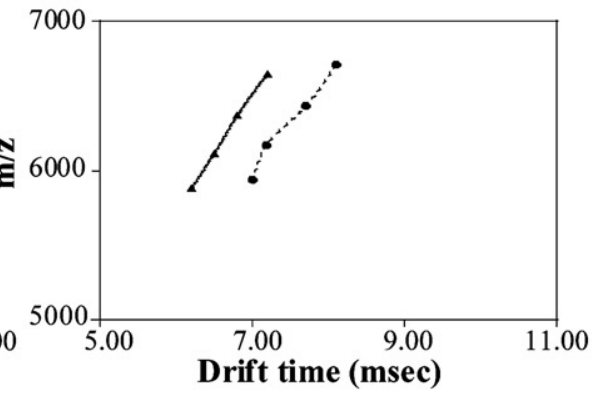

Fig. 4. Plot of ion intensities versus their drift time in the ion mobility mass spectrometer of apo-PKG (a) and holo-PKG (b). Red means most intense. In (c), the drift-time distributions of apo and holo are overlaid for $[M+H]^{27+} ;$ in (d), the mean drift times of each individual charge state are plotted for both apo-PKG $(\mathbf{\Delta})$ and holo-PKG $(\mathbf{\bullet})$, revealing the consistent shift to longer retention time for holo-PKG.

likely originates from differences in overall globular structure. A more open structure leads to a higher collisional cross section and, therefore, slower mobility. Therefore, the observed slower ion mobility of holo-PKG hints at a larger collisional cross section and thus a more open conformation, in line with the expected opening of the structure of PKG in the presence of $\mathrm{CGMP}^{38}$ and in agreement with the observed higher charging of holo-PKG and extended global $\mathrm{H} / \mathrm{D}$ exchange behavior described above. This finding would indicate that the gasphase conformations of apo-PKG and holo-PKG reflect, to some extent, the solution-phase globular structures of the protein.

Next, we focused on site-specific H/D exchange measurements to investigate the exact regions affected by the conformational changes that occur when PKG is activated by cGMP.

\section{Domain-specific H/D exchange measurements pinpoint the conformational changes that occur upon kinase activation}

A solution of PKG was diluted 10-fold in $\mathrm{D}_{2} \mathrm{O}$ in the presence or in the absence of saturating cGMP concentrations. The H/D exchange reaction was stopped after $5 \mathrm{~min}$ by quenching the protein solution with a citric/succinic acid buffer at $\mathrm{pH} 2.5$. Subsequently, the sample was digested with pepsin or type XIII protease. Proteolysis of apo-PKG and holo-PKG was optimized using different digestion times and protease-to-protein ratios in order to obtain peptides in the mass range of $800-6000 \mathrm{Da}$, which are most amendable for MALDI analysis. The optimized conditions were proteolyses at $4{ }^{\circ} \mathrm{C}$ for $1 \mathrm{~min}$ and at a protease-to-protein ratio of 1:1 $(w t / w t)$. From the remarkable number of observed proteolytic products, we were able to confidently use for the H/D exchange analysis 26 pepsin peptides and 19 type XIII peptides that covered $58 \%$ of the sequence. This percentage is a very acceptable sequence coverage considering that PKG is a large protein. In Fig. 5, the mass spectra of some representative proteolytic peptides are shown. Table 1 shows the measured deuterium content of all the peptides after $5 \mathrm{~min}$ of deuteration. All H/D exchange experiments and analyses were repeated at least three times, from which standard deviations in the measured deuterium contents could be calculated. The identity and sequences of all these peptides were confirmed by MALDI MS/MS and, for even higher confidence, by liquid chromatography mass spectrometry/mass spectrometry using an LTQ-Orbitrap instrument (data not shown).

In Fig. 5, the MALDI spectra of four representative peptides of the sequences $80-87,258-279,490-499$ and 568-575 are depicted, all revealing different H/D exchange behaviors in apo-PKG and holo-PKG. The segment $80-87$, which is located in the hinge region, is revealed just as its neighboring segments increased solvent exposure in holo-PKG, as do the segment 568-575 and its neighboring segments, which are all located in the substrate-binding domain. In contrast, the segment 258-279, which is located in the second cGMP-binding pocket domain, becomes less deuterated in holo-PKG, evidencing protection in this 


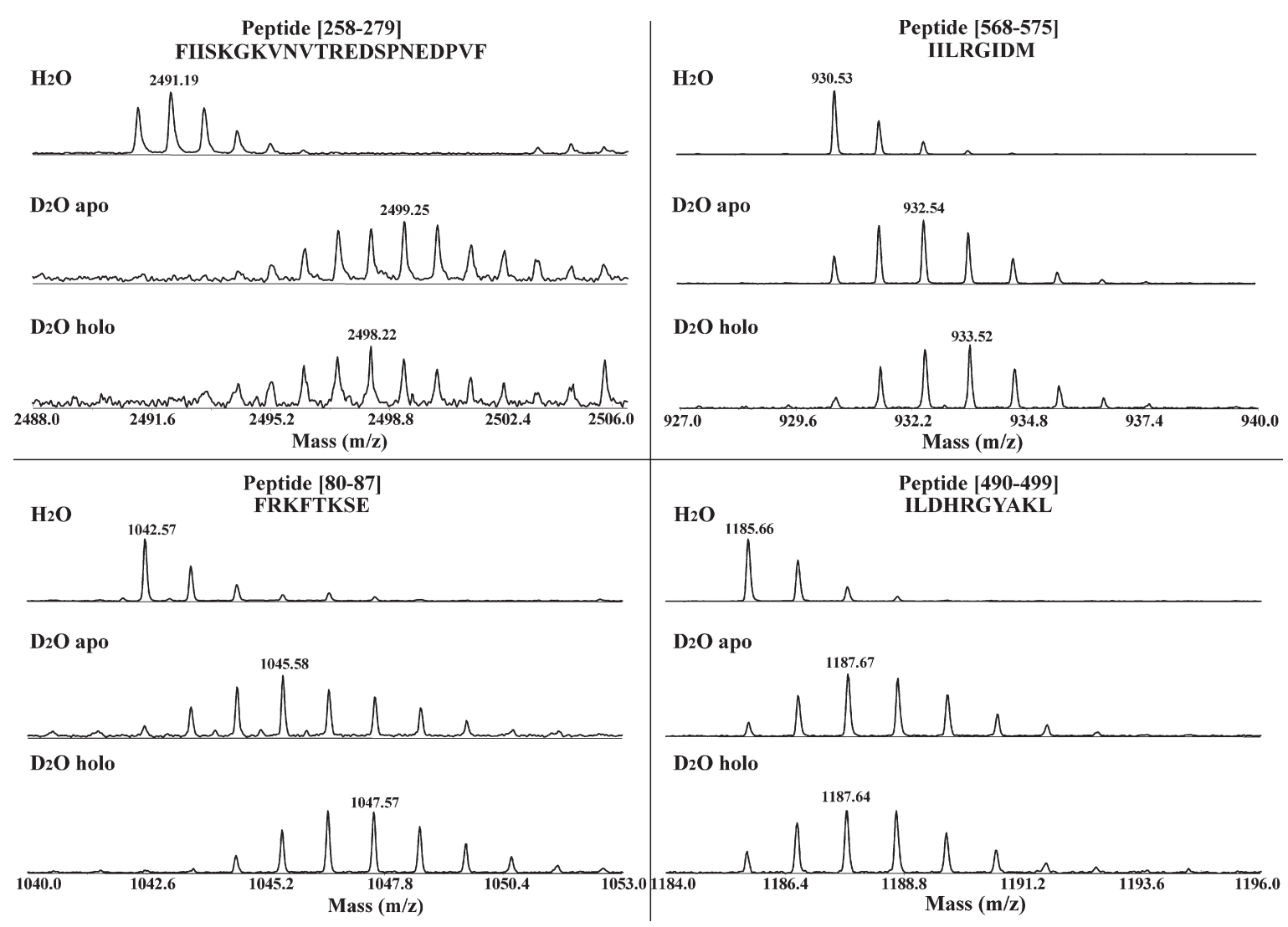

Fig. 5. Examples of peptides detected in our H/D exchange measurements. MALDI mass spectra are shown for the singly charged peptides 258-279, 80-87, 568-575 and 490-499 (within each panel from top to bottom): the peptide of PKG $\mathrm{I} \alpha$ without exchange and with H/D exchange in the case of apo-PKG and holo-PKG, respectively.

region. Finally, the depicted segment 490-499 did not reveal any significant difference in $H / D$ exchange between apo-PKG and holo-PKG.

The bovine PKG I $\alpha$ sequence is given in Fig. 6, whereby we superimposed the detected peptides obtained by pepsin or type XIII proteases. The peptides are color coded, whereby red means more solvent exposure and green means less solvent exposure in holo-PKG. The H/D exchange data summarized in Table 1 and Fig. 6 reveal a wealth of information on differences in the solvent exposure of specific domains of PKG upon cGMP binding. For instance, upon cGMP binding, the N-terminal region of PKG up to the hinge region (residues 1-87) becomes significantly more exposed, at least in the parts of the sequence we were able to investigate. In contrast, nearly all the peptides ( 9 out of 10) covering the two cGMP-binding domains (residues 110-344) revealed significantly more protection upon cGMP binding. Part of the ATP-binding domain (residues 359-390) became significantly more exposed, whereas the end of this domain (residues 407-462) seemed to not exhibit differences upon cGMP binding. Most strikingly, the substratebinding region of the catalytic domain of holo-PKG displayed a dramatic increase in solvent exposure, as highlighted by the data concerning nine peptides in the region 529-655, hinting at the involvement of this region in the activation process of the kinase.

\section{Discussion}

The differential charging under native mass spectrometry conditions, the real-time intact protein $\mathrm{H} / \mathrm{D}$ exchange monitoring and the ion mobility analysis of the global structural differences between apo-PKG and holo-PKG further demonstrate the previously suggested opening of the structure of PKG upon cGMP binding. Under identical mass spectrometric conditions, holo-PKG exchanged up to approximately 190 more backbone and side-chain hydrogen atoms than apo-PKG. Moreover, holoPKG displayed a longer drift time than apo-PKG ions in the ion mobility device, indicating a larger cross section for holo-PKG and thus corroborating the proposed elongation of the holo-form, as established by small-angle X-ray scattering. ${ }^{39,40}$

Since there is no crystal structure reported for either apo-PKG or holo-PKG, data on specific domain interactions in either state of PKG are based on indirect evidence, such as site-directed mutagenesis and/or limited proteolysis. ${ }^{33,37,57,62}$ Both methods are suboptimal, as limited proteolysis provides only general information on very large protein fragments, while mutagenesis allows the study of one-or, at best, a few-amino acid(s) at a time. In addition, mutations may have a dramatic effect on the general protein structure and function, thereby inducing false-positive observations. With 


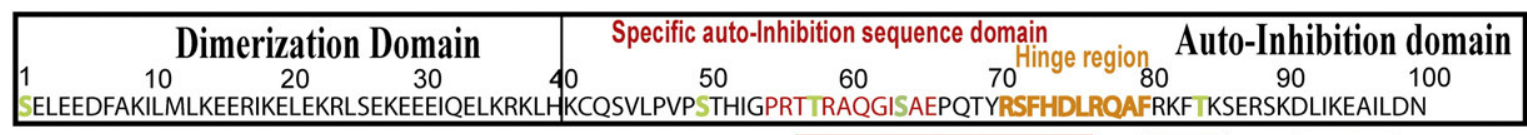

\section{Regulatory domain}

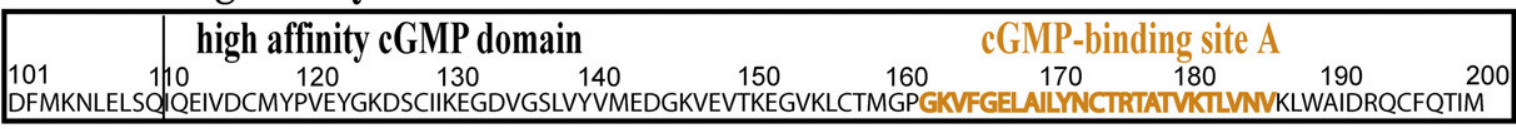

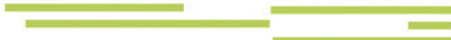

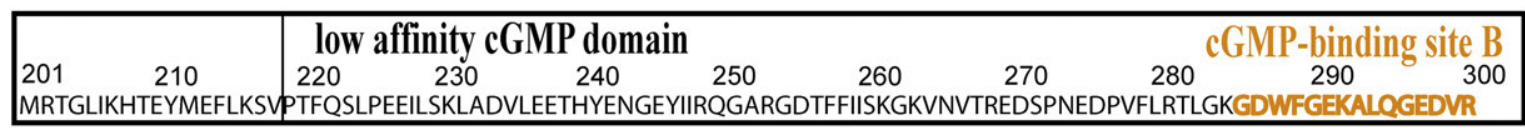

\section{Catalytic domain}

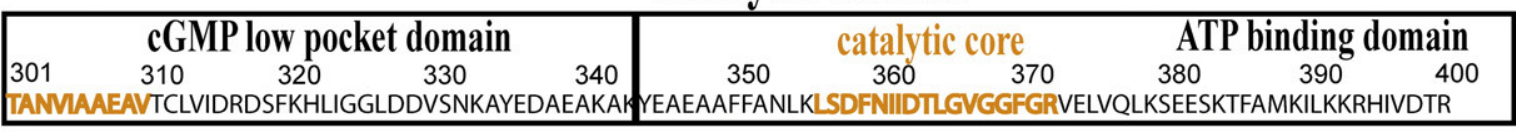

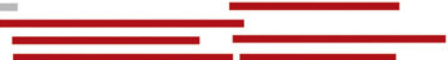

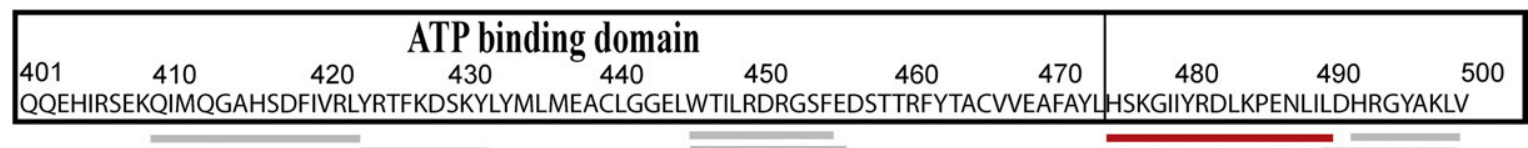

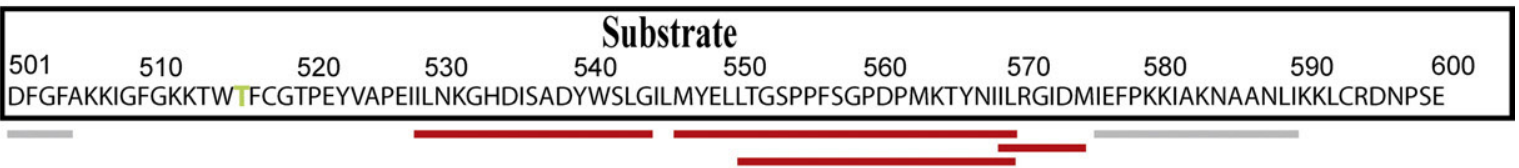

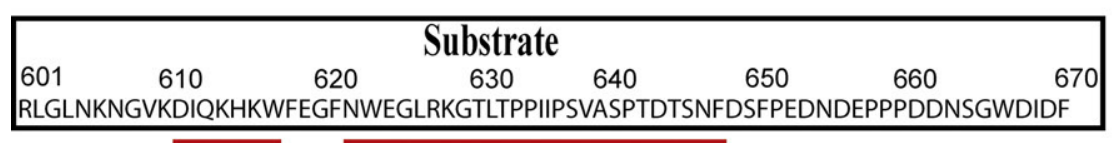

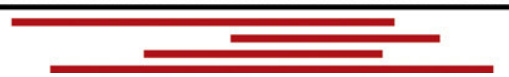

Fig. 6. Summary of the H/D exchange data overlaid over the amino acid sequence of PKG I $\alpha$. Red bars indicate peptides that become more solvent exposed upon cGMP binding. Green bars show peptides that become more protected upon cGMP binding. Gray bars indicate peptides that do not reveal any significant changes.

our HDX-MS approach, for the first time, we were able to study many simultaneous effects of cGMP on the structure of PKG in more detail. The data in Fig. 6 depict a very in-depth view on which particular stretches of the protein sequence become more or less solvent-accessible upon cGMP binding. In Materials and Methods, these data will be put in perspective with data obtained earlier.

Limited proteolysis studies revealed that, upon cGMP binding, the N-terminus of PKG becomes more exposed, as derived from increased susceptibility towards proteolytic cleavage in the hinge region around $R 77.41,57,63$ It has been suggested that only a limited region (i.e., region 77-80) of the N-terminal domain is protease exposed in the inactive state, indicating a tight conformation in which the autoinhibitory site is well protected for proteolysis. ${ }^{57}$ Upon cGMP binding, this tight conformation is relieved; hence, the whole autoinhibitory domain and the hinge region become solvent exposed and, 
Table 1. Average number of exchanged hydrogen atoms in proteolytic peptides of apo-PKG and holo-PKG digested with pepsin or type XIII protease after $5 \mathrm{~min}$ of $\mathrm{H} / \mathrm{D}$ exchange

\begin{tabular}{|c|c|c|c|c|c|}
\hline \multirow[b]{2}{*}{$\underline{\text { Sequence }}$} & \multicolumn{2}{|c|}{$\begin{array}{c}\text { Number } \\
\text { of amide } \\
\text { hydrogen } \\
\text { atoms }\end{array}$} & \multicolumn{2}{|c|}{$\begin{array}{c}\text { Exchanged } \\
\text { hydrogen atoms }\end{array}$} & \multirow{2}{*}{$\begin{array}{c}\Delta \text { Exchange } \\
{\left[\mathrm{nH}_{\mathrm{ex}(\text { holo })}\right.} \\
\left.\mathrm{nH}_{\text {ex (apo) }}\right]\end{array}$} \\
\hline & Pepsin & $\begin{array}{l}\text { Type } \\
\text { XIII }\end{array}$ & Apo-PKG & Holo-PKG & \\
\hline $4-13$ & 10 & & $1.98 \pm 0.03$ & $2.00 \pm 0.01$ & 0.02 \\
\hline $49-56$ & & 8 & $2.00 \pm 0.093$ & $2.25 \pm 0.017$ & 0.25 \\
\hline $57-76$ & & 20 & $7.11 \pm 0.09$ & $8.90 \pm 0.10$ & 1.79 \\
\hline $62-76$ & & 15 & $6.09 \pm 0.03$ & $7.01 \pm 0.02$ & 0.92 \\
\hline $80-85$ & & 6 & $3.21 \pm 0.01$ & $3.93 \pm 0.04$ & 0.72 \\
\hline $80-87$ & & 8 & $4.06 \pm 0.01$ & $5.08 \pm 0.02$ & 1.02 \\
\hline $91-98$ & & 8 & $2.02 \pm 0.04$ & $1.98 \pm 0.02$ & -0.04 \\
\hline $107-113$ & & 7 & $2.93 \pm 0.04$ & $2.06 \pm 0.07$ & -0.87 \\
\hline $113-120$ & & 8 & $4.02 \pm 0.05$ & $2.96 \pm 0.06$ & -1.06 \\
\hline 170-182 & 13 & & $4.93 \pm 0.04$ & $2.95 \pm 0.03$ & -1.98 \\
\hline $172-188$ & 17 & & $6.02 \pm 0.03$ & $3.94 \pm 0.04$ & -2.08 \\
\hline 189-196 & 8 & & $2.99 \pm 0.02$ & $3.01 \pm 0.01$ & 0.02 \\
\hline 189-200 & 12 & & $4.01 \pm 0.02$ & $3.04 \pm 0.02$ & -0.97 \\
\hline $198-215$ & 18 & & $5.06 \pm 0.01$ & $2.11 \pm 0.09$ & -2.95 \\
\hline 258-279 & 21 & & $8.57 \pm 0.01$ & $6.02 \pm 0.01$ & -2.55 \\
\hline $303-313$ & & 11 & $3.01 \pm 0.01$ & $3.47 \pm 0.03$ & 0.46 \\
\hline $307-325$ & 20 & & $6.59 \pm 0.15$ & $5.07 \pm 0.03$ & -1.52 \\
\hline $351-359$ & 9 & & $3.50 \pm 0.02$ & $3.53 \pm 0.02$ & 0.03 \\
\hline $359-375$ & 17 & & $5.49 \pm 0.04$ & $6.00 \pm 0.06$ & 0.51 \\
\hline $360-372$ & & 13 & $5.10 \pm 0.03$ & $5.99 \pm 0.04$ & 0.89 \\
\hline $360-374$ & & 15 & $5.08 \pm 0.02$ & $5.98 \pm 0.03$ & 0.90 \\
\hline $375-386$ & & 12 & $3.09 \pm 0.02$ & $4.98 \pm 0.04$ & 1.89 \\
\hline 375-389 & & 13 & $4.08 \pm 0.06$ & $4.99 \pm 0.04$ & 0.91 \\
\hline $376-386$ & & 11 & $4.10 \pm 0.07$ & $5.97 \pm 0.04$ & 1.87 \\
\hline $410-423$ & 14 & & $4.00 \pm 0.02$ & $4.01 \pm 0.02$ & 0.01 \\
\hline $423-429$ & & 7 & $2.97 \pm 0.02$ & $2.96 \pm 0.03$ & -0.01 \\
\hline $424-432$ & 9 & & $2.98 \pm 0.03$ & $2.99 \pm 0.01$ & 0.01 \\
\hline $446-455$ & 10 & & $2.99 \pm 0.03$ & $3.01 \pm 0.02$ & 0.02 \\
\hline $446-456$ & 11 & & $1.98 \pm 0.03$ & $2.01 \pm 0.03$ & 0.03 \\
\hline $450-462$ & 14 & & $6.05 \pm 0.05$ & $6.01 \pm 0.05$ & -0.04 \\
\hline $475-491$ & 18 & & $7.03 \pm 0.01$ & $9.08 \pm 0.06$ & 2.05 \\
\hline $490-499$ & 10 & & $2.97 \pm 0.03$ & $2.98 \pm 0.02$ & 0.01 \\
\hline $489-499$ & 11 & & $2.99 \pm 0.03$ & $3.02 \pm 0.02$ & 0.03 \\
\hline $490-504$ & 15 & & $2.93 \pm 0.08$ & $2.97 \pm 0.04$ & 0.04 \\
\hline $492-499$ & 8 & & $1.98 \pm 0.03$ & $2.51 \pm 0.02$ & 0.53 \\
\hline $529-546$ & & 17 & $7.02 \pm 0.02$ & $8.96 \pm 0.02$ & 1.94 \\
\hline $547-570$ & 25 & & $3.11 \pm 0.04$ & $6.07 \pm 0.04$ & 2.96 \\
\hline $551-570$ & 21 & & $4.02 \pm 0.03$ & $6.54 \pm 0.03$ & 2.52 \\
\hline $568-575$ & 8 & & $2.01 \pm 0.03$ & $3.09 \pm 0.01$ & 1.08 \\
\hline $576-589$ & 14 & & $5.02 \pm 0.03$ & $5.04 \pm 0.04$ & 0.02 \\
\hline $611-617$ & & 7 & $2.06 \pm 0.02$ & $2.97 \pm 0.01$ & 0.91 \\
\hline $622-648$ & 28 & & $8.07 \pm 0.1$ & $10.10 \pm 0.01$ & 2.03 \\
\hline $624-654$ & & 31 & $8.12 \pm 0.09$ & $11.20 \pm 0.07$ & 3.08 \\
\hline $630-647$ & & 18 & $3.04 \pm 0.04$ & $4.94 \pm 0.01$ & 1.90 \\
\hline $638-651$ & 14 & & $2.98 \pm 0.03$ & $4.53 \pm 0.08$ & 1.55 \\
\hline
\end{tabular}

thus, protease susceptible. Our data firmly establish that the region 57-88 becomes more solvent exposed in holo-PKG. This result is consistent with the proposed tight interaction in apo-PKG between the autoinhibitory sequence and the catalytic domain through I63.62

Proteolytic peptides from the cGMP-binding domains experienced significant protection upon cGMP binding of holo-PKG. The recent published structural information about the PKA holo-enzyme, in combination with mutagenesis at the two conservative sites, Glu261 and Arg366, involved in the holo-enzyme-specific salt bridge that is important for PKA activation, provided a molecular mechanism for the ordered and cooperative activation of PKA by cAMP, as described by Kim et al. ${ }^{63,64}$ The structures demonstrate the mobility of the cAMP-binding domains in the regulatory subunit type I $\alpha$, remarking the large movement of domain B (high-affinity site for cAMP) relative to domain A (low-affinity site for cAMP). H/D exchange studies on the RI $\alpha$ subunit of PKA in the absence of cAMP and in the presence of cAMP or the catalytic subunit have shown an expected solvent protection of the region 202-221 (cAMP-binding site A) when cAMP is bound on the protein. ${ }^{16}$ The region 199-202 involving the helix motif in the cAMP-binding site appeared not to be very solvent exposed even in the absence of cAMP. When cAMP is removed and the C-subunit is bound to the $\mathrm{RI} \alpha$, the residues 204-221 highlight a further increase in amide deuterium exchange in the binding site. Maybe the binding of the C-subunit induces an increased backbone dynamics in the cAMP-binding pocket. Supplementary Fig. 2 reports the sequence alignment of PKG and PKA RI $\alpha$.

As is possible to observe in Fig. 6 of the article, the peptides 170-182 and 172-188 covered a region corresponding to the cGMP-binding site A (based on PKA structure). In holo-PKG, these segments become more solvent protected, highlighting the protection of this region. This could be comparable with the protection of the corresponding region in the holo-PKA. However, it is important to consider that the order of the high-affinity and low-affinity sites in PKG and PKA is reversed. Maybe this reverse order could influence the global movement of this domain and the catalytic one, even if, in the absence of PKG structure, it is still really difficult to compare properly the data already known about PKA.

The catalytic domain of PKG consists, as in most eukaryotic kinases, of a two-lobed catalytic core, one small lobe with the ATP-binding site and a large lobe that includes the substrate-binding domain and the catalytic site. Using available detailed structural information on the related, albeit structurally quite different, PKA kinase, we tried to interpret the data obtained on PKG. It should be kept in mind that, upon activation by cAMP, the catalytic subunits dissociate from the regulatory domains in PKA, whereas this evidently cannot happen similarly in cGMP-activated PKG. Therefore, we believe that a direct comparison between PKA and PKG is interesting but only of limited value. The catalytic core of PKG is in the segment 356-372. The glycinerich GXGGXXGXV motif that functions as a hydrophobic pocket is able to bind the adenine ring of ATP. This sequence is followed by a linker region 431-454 that operates as a connection between the two lobes of the catalytic domain. ${ }^{65,66}$ In PKA, ATP becomes bound inside the cleft between the smaller lobe and the larger lobe of the catalytic domain. The opening and closing of this cleft serve to properly position ATP for catalysis. For apo-PKG, it was proposed that the interaction between the autoinhibitory domain and the substrate-binding domain 
might stabilize the flexibility in the opening and the closing of the active cleft. ${ }^{56}$ Our data demonstrated that, in holo-PKG, the catalytic core became more solvent exposed, whereas the linker region did not reveal any significant change in H/D exchange. This might indicate that, in the cGMP-activation process, ATP binding is altered (i.e., more exposed, as described by Hofmann et al.). ${ }^{36}$ However, there is evidence in the literature about the binding of ATP to the active and inactive enzymes. The data reported by Pinkse et al. demonstrate the possible binding of ATP to apo-PKG, however only in the presence of a divalent metal ion such as $\mathrm{Mg}^{2+}$ or $\mathrm{Mn}^{2+} .56$

Next, our H/D exchange data reveal that specifically the catalytic loop 481-488 in the substrate domain, where D483 plays the role of proton acceptor of the $\mathrm{S}$ and $\mathrm{Y}$ hydroxyl groups and where the residue K485 facilitates phosphotransfer by neutralizing the $\gamma$-phosphate, ${ }^{65}$ becomes more solvent exposed in holo-PKG, whereas the adjacent region 491-504 was not altered. Finally, a large part of the C-terminal lobe of the catalytic domain (i.e., regions 529-575 and 611-655) that constitutes the substrate-binding domain becomes significantly more exposed in holo-PKG, possibly facilitating substrate binding. These conformational changes are new insights for PKG upon cGMP binding. While in PKA the catalytic subunit is released from the regulatory subunit upon cAMP binding, in PKG, the region of the substrate-binding domain becomes more solvent exposed upon cGMP binding. ${ }^{16}$ Most of the determinants necessary for substrate-binding specificity are located in the larger amino-terminal lobe. Substrate recognition plays a key role in the determination of protein kinase specificity. The primary sequence requirements for substrates of PKA/ PKG follow the motif RRX-S/T-X. Even as the level of homology between the catalytic cores of PKA and PKG is quite high, the difference in their target substrate specificity may demonstrate that the peptidebinding site of PKG differs substantially from that of PKA, considering that the kinase specificity for substrates is largely determined by the substratebinding domain. The comparison of the substratebinding domains in PKA and PKG shows that only $47 \%$ of the residues in the large lobe of the catalytic subunit are conserved in the two kinases, ${ }^{27}$ which may partly explain the observed differences in conformational dynamics.

Many studies on the ability of the catalytic subunit of PKA to behave as a scaffold for docking to different proteins (substrates) have been done in order to clarify the interactions between the different subunits of the kinase. ${ }^{66-69}$ Structural studies with the high-affinity inhibitor peptide PKI bound to PKA-C revealed precisely how it docks to the active site cleft, combining the two lobes of PKA-C in an inhibited complex that cannot perform catalysis. It was also shown for PKA-C that, in order to obtain a high-affinity binding to substrates (or inhibitory peptides such as PKI), the presence of a second hydrophobic site on the large lobe of the catalytic domain of PKA is required. ${ }^{5}$ This peripheral site is also referred to as the substrate-tethering region. In addition to the docking of the inhibitor peptide to the active site cleft, in PKA-C, the activation loop and the $G$ helix of the catalytic domain play a key role in the inhibition of PKA-C by PKA-R.

For PKA-C, HDX-MS demonstrated the increased stability of the three helices E, F and H of the large lobe of the catalytic domain, whereas the $G$ helix appeared much more solvent exposed upon inhibitor (substrate peptide) binding. 5,17 This indicates a major flexibility of this region after inhibitor (substrate) binding. In conclusion, the flexibility of the $G$ helix and the loop between the F helix and the G helix can be explained considering that these two motifs are the docking regions for PKI.

Considering the homology between PKA and PKG and taking into account the lack of structural details for the last one, we have investigated the sequence homology between PKA and PKG in the substratetethering region. PKA-C and PKG sequence alignments in the region of the $\mathrm{E}, \mathrm{F}, \mathrm{G}$ and $\mathrm{H}$ helices on the large lobe in the catalytic domains of these kinases showed an identity of $49.6 \%$ (see Supplementary Fig. 1). We have good coverage of the region that corresponds to the $\mathrm{F}$ and $\mathrm{G}$ helices, with the peptides 529-546, 547-570 and 568-575 identified in the large lobe of the catalytic domain of PKG with our H/D exchange measurements. These peptides become more solvent exposed in the holoenzyme, indicating an increase in the solvent exposure of this region upon cGMP binding. The solvent exposure shown in our data in the region between the F, G and $\mathrm{H}$ helices is not easily comparable with the abundant structural data reported for PKA. It might be considered that the solvent exposure of the G helix observed when PKI is bound to the C-subunit of PKA decreases after the activation process. ${ }^{15}$ In the case of PKA, the dissociation of the two subunits ( $R$ and $C$ ) plays a very important role in the solvent exposure of this region. The subsequent peptides 576-589 that might correspond to the region involving the loop between the $G$ and $\mathrm{H}$ helices and the $\mathrm{H}$ helix in the PKA structure became solvent exposed in both apo-PKA and holo-PKA.

The lack of structural details for PKG plays a key role in this discussion; indeed, some of the data presented in our paper are not completely explainable by PKA structure comparison. However, the complete structural information already published about PKA complexes made the discussion more complete.

The C-terminal tail of PKA (residues 299-351) and PKG (residues 620-671) is highly conserved in all the AGC kinases. The already published data on PKA about this region presented a C-terminal tail anchored to the large lobe of the catalytic domain by residues 301-316 and anchored to the small lobe by the C-terminal hydrophobic segment (residues 347-350), with the two motifs being very conserved in the AGC kinases. Moreover, in this region, there are residues involved in ATP binding and substrate recognition (segment 327-336). 
The sequence alignment of these two regions in PKG and PKA has shown an identity of only $36.5 \%$ (Supplementary Fig. 1).

The H/D exchange on peptides 624-654 (see Fig. 6 in the article) identified in the AGC domain of PKG becomes more solvent exposed after activation by cGMP binding.

The different behavior observed for PKG in this region could be attributed to the single polypeptide chain that allows different hypothetical structural movements of the catalytic domain after enzyme activation, compared to the structure of PKA characterized from different subunits that dissociate during the activation process. Furthermore, it is important to consider that ATP binds PKG in the presence and in the absence of cGMP, and maybe the presence of ATP on the site cleft of the protein could protect the C-terminal region involved in the binding.

In conclusion, the few structural data available for PKG, not the high level of homology of the C-terminal tails of PKG and PKA and the absence of ATP bound to the PKG in our H/D exchange experiments, did not facilitate the comparison of the behaviors of the two conserved C-terminal tails. Future studies focusing on the active and inactive PKG in the presence or in the absence of ATP could improve the preliminary conformational information regarding the changes that occur on PKG in the presence of cGMP.

Summarizing our data, we propose a new structural model for the cGMP-induced activation of PKG, which is schematically depicted in Fig. 7. In this model, we describe that, upon cGMP binding, the autoinhibitory domain detaches from the substrate-binding lobe of the catalytic domain, exposing the larger catalytic lobe and facilitating substrate binding. Concomitantly, ATP binding shows an increase in surface exposure. We conclude that cGMP binding to PKG seems to induce a multi- faceted structural conformational change that is required for the activation of the kinase.

\section{Materials and Methods}

\section{Sample preparation}

The gene encoding PKG-I $\alpha^{22}$ was isolated from pcDNA3.1 using BamHI and NotI, and ligated into a pTT3 expression vector. ${ }^{70}$ Suspension-growing HEK293EBNA1 cells were transiently transfected with pTT3-PKG$\mathrm{I} \alpha$ and polyethyleneimine in accordance with Durocher et al. ${ }^{70}$ Cells were harvested by centrifugation at 5 days posttransfection $\left(30 \mathrm{~min}, 1000 \mathrm{~g}, 4{ }^{\circ} \mathrm{C}\right)$; the cells were resuspended in $1 \mathrm{~g} / 10 \mathrm{~mL}$ cold lysis buffer [ $25 \mathrm{mM} \mathrm{KHPO}_{4}$ (pH 6.8), $10 \mathrm{mM}$ DTT, $10 \mathrm{mM}$ ethylenediaminetetraacetic acid (EDTA), $10 \mathrm{mM}$ benzamidine and $100 \mathrm{mM} \mathrm{NaCl}$ ] and frozen in liquid $\mathrm{N}_{2}$. The pellet was thawed by 5-min incubation at $37{ }^{\circ} \mathrm{C}$, and the freeze step was repeated twice. The lysate was centrifuged at 50,000 rpm for $30 \mathrm{~min}$ at $4{ }^{\circ} \mathrm{C}$.

Purification was largely performed as reported earlier for PKG I $\alpha$ expressed in the baculovirus expression system. $^{71}$ Briefly, the supernatant was loaded on a preequilibrated 8-AEA-cAMP agarose column (Biolog, Bremen, Germany). A cyclic-nucleotide-free fraction of PKG, after undergoing extensive washing, was eluted with several batches of $3 \mathrm{M} \mathrm{NaCl}$. Subsequently, the remaining PKG was eluted with a solution of $500 \mu \mathrm{M}$ cAMP in $25 \mathrm{mM} \mathrm{KHPO}_{4}$ (pH 6.8), $10 \mathrm{mM}$ DTT, $10 \mathrm{mM}$ EDTA, $10 \mathrm{mM}$ benzamidine and $150 \mathrm{mM} \mathrm{NaCl}$. The cyclicnucleotide-free fraction was pooled, concentrated and buffer exchanged with storage buffer $(50 \mathrm{mM} \mathrm{KHPO}$, $2 \mathrm{mM}$ EDTA, $5 \mathrm{mM}$ DTT, $2 \mathrm{mM}$ benzamidine, $150 \mathrm{mM}$ $\mathrm{NaCl}$ and $50 \%$ glycerol) on a $5-\mathrm{kDa}$ Beckman centrifugal concentrator up to a final concentration of $0.4 \mathrm{mg} / \mathrm{mL}$ PKG.

PKG activity was determined by probing for phosphorylation activity in the presence of ATP $/ \mathrm{Mg}^{2+}$ and cAMP.

Before $\mathrm{H} / \mathrm{D}$ exchange, native mass spectrometry and ion mobility mass spectrometry, PKG was buffer exchanged with a volatile buffer containing $200 \mathrm{mM}$ ammonium
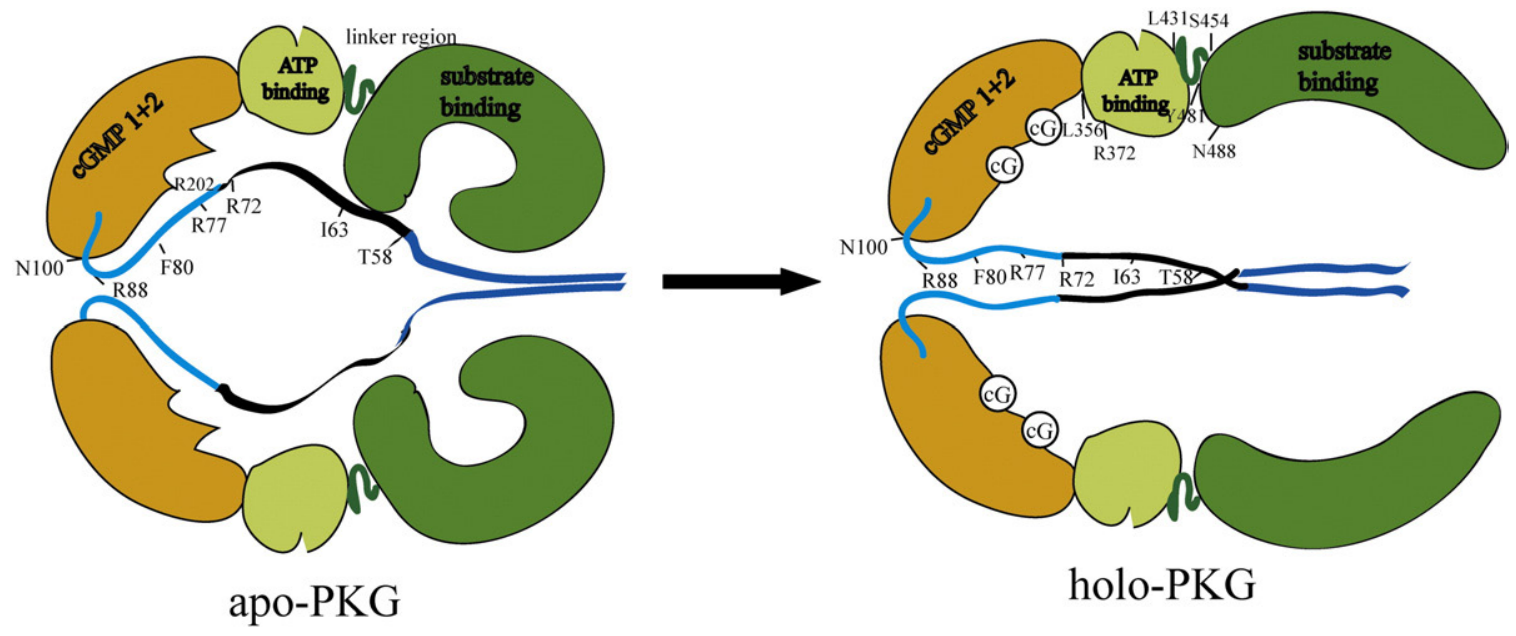

Fig. 7. Schematic model of the proposed conformational reorientation that occurs in PKG I $\alpha$ upon cGMP binding. The $\mathrm{N}$-terminus region is depicted in detail to show the involvement of the autoinhibitory domain T57-R88, including the hinge region R77-F80 in the proposed conformational changes. The model describes the gain in solvent accessibility of the ATP-binding site and the substrate-binding domain upon cGMP binding as potential collective factors in kinase activation. 
acetate $/ \mathrm{H}_{2} \mathrm{O}(\mathrm{pH}$ 6.8) with ultrafree- 0.5 centrifugal filter units $(10,000$ nominal molecular weight limit) (Millipore, Bedford, MA) at a final concentration of $50 \mu \mathrm{M}$. cGMP, dissolved in the same buffer, was added in a ratio of 1:5 or 1:10 (dimeric PKG:cGMP) to the PKG solution and incubated on ice for $5 \mathrm{~min}$.

\section{Global H/D exchange monitored by ESI-MS}

PKG (dimer concentration of $50 \mu \mathrm{M}$ ) in $200 \mathrm{mM}$ ammonium acetate $/ \mathrm{H}_{2} \mathrm{O}$ buffer ( $\mathrm{pH}$ 6.8), in the presence or in the absence of cGMP, was diluted 10 times into $200 \mathrm{mM}$ ammonium acetate $/ \mathrm{D}_{2} \mathrm{O}$ buffer $(\mathrm{pD}=6.8$; $\mathrm{pD}$ values are the values read from a $\mathrm{pH}$ meter with no adjustment for isotopic effects ${ }^{72}$ ) to obtain a final $\mathrm{D}_{2} \mathrm{O}$ percentage of $90 \%$. The mass spectrometry measurements were performed using an ESI time-of-flight (TOF) instrument LCT equipped with a Z-spray nanoflow electrospray source (Micromass UK Ltd., Manchester, UK). Two microliters of the protein solution was infused into the mass spectrometer using an in-house pulled and goldcoated borosilicate glass needle. Typical ESI-TOF-MS parameters were as follows: capillary voltage, $1.5 \mathrm{kV}$; sample cone voltage, $150 \mathrm{~V}$; extraction cone voltage, $50 \mathrm{~V}$; source pressure, $8.2 \mathrm{mbar}$; TOF analyzer, $1.2 \times 10^{-6} \mathrm{mbar}$. Spectra were recorded in the positive ion mode between $m / z 500$ and 10,000 . For mass calibration, an aqueous CsI solution was used at a concentration of $20 \mathrm{mg} / \mathrm{mL}$. The spectra were processed using MassLynx V4.1 Software (Micromass UK Ltd.)

The total number of exchangeable hydrogen atoms of PKG was calculated from its amino acid sequence, being 2138 in $90 \%$ of $\mathrm{D}_{2} \mathrm{O}$ out of a total of 2376 . The combined data from several charge states of the protein in each spectrum were used to calculate the molecular mass.

\section{Ion mobility mass spectrometry analysis}

A modified quadrupole TOF mass spectrometer (Q-Tof; Waters, Manchester, UK) ${ }^{73}$ was used for measuring the ion mobility of apo-PKG and holo-PKG. The solutions of apo-PKG and holo-PKG (PKG:cGMP ratios of 1:5 and 1:10) were injected at a concentration of $2.5 \mu \mathrm{M}$. Nano-ESI generated the ions that were trapped in the first traveling wave (T-wave) ion guide device, in our case for $50 \mathrm{~ms}$. When the ions came out, they traveled in the second T-wave that worked as an ion mobility separator. At the end, the ions were directed into an OA-TOF mass spectrometer for mass analysis. The wave height (maximum voltage) and the velocity of the traveling waves are parameters that we can change in order to improve the separation of the ions. We acquired the spectra for apoPKG and holo-PKG at two different wave heights, 8 and $12 \mathrm{~V}$. External calibration of the mass spectra was achieved using solutions of CsI. The spectra were acquired and analyzed with MassLynx V4.1 Software (Micromass UK Ltd.).

\section{Site-specific H/D exchange monitored by MALDI-MS}

PKG (dimer concentration of $50 \mu \mathrm{M}$ ) in $200 \mathrm{mM}$ ammonium acetate $/ \mathrm{H}_{2} \mathrm{O}$ buffer $(\mathrm{pH}$ 6.8) was diluted 10 times into $\mathrm{D}_{2} \mathrm{O}$ (a $99.9 \%$ pure solution of $\mathrm{D}_{2} \mathrm{O}$; Aldrich) in the presence or in the absence of cGMP. The deuterated samples were incubated on ice for $5 \mathrm{~min}$, and an aliquot of $10 \mu \mathrm{L}$ was mixed with $40 \mu \mathrm{L}$ of ice-cold quench solution (citric acid/succinic acid 1:1, $50 \mathrm{mM}, \mathrm{pH} 2.5$ ) and $5 \mu \mathrm{L}$ of pepsin beads slurry (pepsin beads from Pierce). The final $\mathrm{pD}$ of this solution was 2.5 , which quenched the H/D exchange. The sample was centrifuged on a BioRad filter in order to remove the beads and to stop the cleavage reaction. The same protocol was used with the type XIII protease from Aspergillus satoi; the aliquot of deuterated sample was mixed with $40 \mu \mathrm{L}$ of ice-cold quench solution and type XIII protease in a PKG:protease ratio of 1:1 $(w t / w t)$. The samples were immediately frozen in liquid $\mathrm{N}_{2}$ and stored at $-80^{\circ} \mathrm{C}$ until MALDI-MS analysis.

\section{MALDI-MS analysis of digest peptides}

MALDI-MS analysis was performed with a MALDI TOF-TOF instrument (4700 Proteomics analyzer; Applied Biosystems), and the matrix was $5 \mathrm{mg} / \mathrm{mL} \alpha$-cyano-4hydroxycinnaminic acid (Sigma) in 1:1:1 solution $(0.2 \%$ trifluoro acetic acid:ethanol:acetonitrile) at $\mathrm{pH} 2.5$. The digested mixtures were rapidly thawed and mixed 1:1 with the cold matrix solution. The mixtures were quickly spotted on the MALDI plate under nitrogen flow and analyzed. The spectra were acquired in positive and reflectron ion modes in the $m / z$ range 800-6000. About 1500-3500 shots were averaged for each spectrum. Data were acquired at a laser repetition rate of $200 \mathrm{~Hz}$, an acceleration voltage of $20 \mathrm{kV}$, a grid voltage of $70 \%$ and a digitizer bin size of $0.5 \mathrm{~ns}$. The calibration of the spectra was done using a standard peptide calibration mixture (Applied Biosystems). Each digested mixture solution was spotted in three different spots, two spectra per spot were acquired and the experiment was repeated at least three times. The mass accuracy of the instrument was between $25 \mathrm{ppm}$ and $50 \mathrm{ppm}$.

Data analysis was performed with the data explorer ${ }^{\mathrm{TM}}$ software version 4.5 (Applied Biosystems). The number of deuterium molecules exchanged in the peptide during the incubation in $\mathrm{D}_{2} \mathrm{O}$ was calculated from the centroid of the isotopic peak envelope. In order to calculate the difference between apo-PKG and holo-PKG, we applied the difference between the number of deuterium molecules exchanged in the apo-protein and the number of deuterium molecules exchanged in the holo-protein.

\section{Supplementary Data}

Supplementary data associated with this article can be found, in the online version, at doi:10.1016/ j.jmb.2007.11.053

\section{References}

1. Garbers, D. L. (1992). Guanylyl cyclase receptors and their endocrine, paracrine, and autocrine ligands. Cell, 71, 1-4.

2. Lincoln, T. M., Dey, N. \& Sellak, H. (2001). cGMPdependent protein kinase signaling mechanisms in smooth muscle: from the regulation of tone to gene expression. J. Appl. Physiol. 91, 1421-1430.

3. Geiger, J., Nolte, C., Butt, E., Sage, S. O. \& Walter, U. (1992). Role of cGMP and cGMP-dependent protein kinase in nitrovasodilator inhibition of agonist-evoked calcium elevation in human platelets. Proc. Natl Acad. Sci. USA, 89, 1031-1035.

4. Gambaryan, S., Geiger, J., Schwarz, U. R., Butt, E., Begonja, A., Obergfell, A. \& Walter, U. (2004). Potent inhibition of human platelets by cGMP analogs 
independent of cGMP-dependent protein kinase. Blood, 103, 2593-2600.

5. Taylor, S. S., Kim, C., Vigil, D., Haste, N. M., Yang, J., Wu, J. \& Anand, G. S. (2005). Dynamics of signaling by PKA. Biochim. Biophys. Acta, 1754, 25-37.

6. Taylor, S. S., Yang, J., Wu, J., Haste, N. M., RadzioAndzelm, E. \& Anand, G. S. (2004). PKA: a portrait of protein kinase dynamics. Biochim. Biophys. Acta, 1697, 259-269.

7. Zheng, J., Knighton, D. R., Ten Eyck, L. F., Karlsson, R., Xuong, N., Taylor, S. S. \& Sowadski, J. M. (1993). Crystal structure of the catalytic subunit of cAMPdependent protein kinase complexed with MgATP and peptide inhibitor. Biochemistry, 32, 2154-2161.

8. Madhusudan, Akamine, P., Xuong, N. H. \& Taylor, S. S. (2002). Crystal structure of a transition state mimic of the catalytic subunit of cAMP-dependent protein kinase. Nat. Struct. Biol. 9, 273-277.

9. Akamine, P., Madhusudan, Wu, J., Xuong, N. H., Ten Eyck, L. F. \& Taylor, S. S. (2003). Dynamic features of cAMP-dependent protein kinase revealed by apoenzyme crystal structure. J. Mol. Biol. 327, 159-171.

10. Kim, C., Xuong, N. H. \& Taylor, S. S. (2005). Crystal structure of a complex between the catalytic and regulatory (RIalpha) subunits of PKA. Science, 307, 690-696.

11. Li, M., Wang, X., Meintzer, M. K., Laessig, T., Birnbaum, M. J. \& Heidenreich, K. (2000). Cyclic AMP promotes neuronal survival by phosphorylation of glycogen synthase kinase 3beta. Mol. Cell. Biol. 20, 9356-9363.

12. Li, F., Gangal, M., Juliano, C., Gorfain, E., Taylor, S. S. \& Johnson, D. A. (2002). Evidence for an internal entropy contribution to phosphoryl transfer: a study of domain closure, backbone flexibility, and the catalytic cycle of cAMP-dependent protein kinase. J. Mol. Biol. 315, 459-469.

13. Das, R., Esposito, V., Abu-Abed, M., Anand, G. S. Taylor, S. S. \& Melacini, G. (2007). cAMP activation of PKA defines an ancient signaling mechanism. Proc. Natl Acad. Sci. USA, 104, 93-98.

14. Banky, P., Roy, M., Newlon, M. G., Morikis, D., Haste, N. M., Taylor, S. S. \& Jennings, P. A. (2003). Related protein-protein interaction modules present drastically different surface topographies despite a conserved helical platform. J. Mol. Biol. 330, 1117-1129.

15. Anand, G. S., Law, D., Mandell, J. G., Snead, A. N., Tsigelny, I., Taylor, S. S., Ten Eyck, L. F. \& Komives, E. A. (2003). Identification of the protein kinase A regulatory RIalpha-catalytic subunit interface by amide $\mathrm{H} / 2 \mathrm{H}$ exchange and protein docking. Proc. Natl Acad. Sci. USA, 100, 13264-13269.

16. Anand, G. S., Hughes, C. A., Jones, J. M., Taylor, S. S. \& Komives, E. A. (2002). Amide $\mathrm{H} / 2 \mathrm{H}$ exchange reveals communication between the cAMP and catalytic subunit-binding sites in the R(I)alpha subunit of protein kinase A. J. Mol. Biol. 323, 377-386.

17. Yang, J., Garrod, S. M., Deal, M. S., Anand, G. S., Woods, V. L. J. \& Taylor, S. S. (2005). Allosteric network of cAMP-dependent protein kinase revealed by mutation of Tyr204 in the P+1 loop. J. Mol. Biol. 346, 191-201.

18. Burns-Hamuro, L. L., Hamuro, Y., Kim, J. S., Sigala, P., Fayos, R., Stranz, D. D. et al. (2005). Distinct interaction modes of an AKAP bound to two regulatory subunit isoforms of protein kinase A revealed by amide hydrogen/deuterium exchange. Protein Sci. 14, 2982-2992.
19. Hamuro, Y., Burns, L., Canaves, J., Hoffman, R., Taylor, S. S. \& Woods, V. (2002). Domain organization of D-AKAP2 revealed by enhanced deuterium exchange-mass spectrometry (DXMS). J. Mol. Biol. 321, 703-714.

20. Hamuro, Y., Anand, G. S., Kim, J. S., Juliano, C., Stranz, D. D., Taylor, S. S. \& Woods, V. L. J. (2004). Mapping intersubunit interactions of the regulatory subunit (RIalpha) in the type I holoenzyme of protein kinase A by amide hydrogen/deuterium exchange mass spectrometry (DXMS). J. Mol. Biol. 340, 1185-1196.

21. Feil, S., Zimmermann, P., Knorn, A., Brummer, S., Schlossmann, J., Hofmann, F. \& Feil, R. (2005). Distribution of cGMP-dependent protein kinase type I and its isoforms in the mouse brain and retina. Neuroscience, 135, 863-868.

22. Wernet, W., Flockerzi, V. \& Hofmann, F. (1989). The cDNA of the two isoforms of bovine cGMP-dependent protein kinase. FEBS Lett. 251, 191-196.

23. Uhler, M. D. (1993). Cloning and expression of a novel cyclic GMP-dependent protein kinase from mouse brain. J. Biol. Chem. 268, 13586-13591.

24. Vaandrager, A. B., Hogema, B. M. \& de Jonge, H. R. (2005). Molecular properties and biological functions of cGMP-dependent protein kinase II. Front. Biosci. 10, 2150-2164.

25. Wolfe, L., Corbin, J. D. \& Francis, S. H. (1989). Characterization of a novel isozyme of cGMP-dependent protein kinase from bovine aorta. J. Biol. Chem. 264, 7734-7741.

26. Wolfe, L. \& Corbin, J. D. (1989). Cyclic nucleotides and disease. Curr. Opin. Cell Biol. 1, 215-219.

27. Takio, K., Wade, R. D., Smith, S. B., Krebs, E. G., Walsh, K. A. \& Titani, K. (1984). Guanosine cyclic 3', 5'phosphate dependent protein kinase, a chimeric protein homologous with two separate protein families. Biochemistry, 23, 4207-4218.

28. Doskeland, S. O., Vintermyr, O. K., Corbin, J. D. \& Ogreid, D. (1987). Studies on the interactions between the cyclic nucleotide-binding sites of cGMP-dependent protein kinase. J. Biol. Chem. 262, 3534-3540.

29. Corbin, J. D., Ogreid, D., Miller, J. P., Suva, R. H., Jastorff, B. \& Doskeland, S. O. (1986). Studies of cGMP analog specificity and function of the two intrasubunit binding sites of cGMP-dependent protein kinase. J. Biol. Chem. 261, 1208-1214.

30. Landgraf, W. \& Hofmann, F. (1989). The amino terminus regulates binding to and activation of cGMP-dependent protein kinase. Eur. J. Biochem. 181, 643-650.

31. Scott, J. D., Fisher, E. H., Demaille, J. G. \& Krebs, E. G. (1985). Identification of an inhibitory region of the heat-stable protein inhibitor of the cAMPdependent protein kinase. Proc. Natl Acad. Sci. USA, 82, 4379-4383.

32. Mitchell, R. D., Glass, D. B., Wong, C. W., Angelos, K. L. \& Walsh, D. A. (1995). Heat-stable inhibitor protein derived peptide substrate analogs: phosphorylation by cAMP-dependent and cGMP-dependent protein kinase. Biochemistry, 34, 528-534.

33. Busch, J. L., Bessay, E. P., Francis, S. H. \& Corbin, J. D. (2002). A conserved serine juxtaposed to the pseudosubstrate site of type I CGMP-dependent protein kinase contributes strongly to autoinhibition and lower cGMP affinity. J. Biol. Chem. 277, 34048-34054.

34. Francis, S. H., Smith, J. A., Colbran, J. L., Grimes, K., Walsh, K. A., Kumar, S. \& Corbin, J. D. (1996). Arginine 75 in the pseudosubstrate sequence of type Ibeta cGMP-dependent protein kinase is critical 
for autoinhibition, although autophosphorylated serine 63 is outside this sequence. J. Biol. Chem. 271, 20748-20755.

35. Yuasa, K., Michibata, H., Omori, K. \& Yanaka, N. (2000). Identification of a conserved residue responsible for the autoinhibition of cGMP-dependent protein kinase Ialpha and beta. FEBS Lett. 466, 175-178.

36. Hofmann, F., Gensheimer, H. P. \& Gobel, C. (1985). cGMP-dependent protein kinase. Autophosphorylation changes the characteristics of binding site 1. Eur. J. Biochem. 147, 361-365.

37. Chu, D. M., Francis, S. H., Thomas, J. W., Maksymovitch, E. A., Fosler, M. \& Corbin, J. D. (1998). Activation by autophosphorylation or cGMP binding produces a similar apparent conformational change in cGMP-dependent protein kinase. J. Mol. Chem. 273, 14649-14656.

38. Francis, S. H., Poteet-Smith, C., Busch, J. L., RichieJannetta, R. \& Corbin, J. D. (2002). Mechanisms of autoinhibition in cyclic nucleotide-dependent protein kinases. Front. Biosci. 7, d580-d592.

39. Zhao, J., Trewhella, J., Corbin, J., Fransis, S., Mitchell, R., Brushia, R. \& Walsh, D. (1997). Progressive cyclic nucleotide-induced conformational changes in the cGMP-dependent protein kinase studies by small angle X-ray scattering in solution. J. Biol. Chem. 272, 31929-31936.

40. Wall, M. E., Francis, S. H., Corbin, J. D., Grimes, K., Richie-Jannetta, R., Kotera, J. et al. (2003). Mechanisms associated with cGMP binding and activation of cGMP-dependent protein kinase. Proc. Natl Acad. Sci. USA, 100, 2380-2385.

41. Chu, D. M., Corbin, J. D., Grimes, K. A. \& Francis, S. H. (1997). Activation by cyclic GMP binding causes an apparent conformational change in cGMP-dependent protein kinase. J. Mol. Biol. 272, 31922-31928.

42. Heck, A. J. R. \& van den Heuvel, R. H. H. (2004). Investigation of intact protein complexes by mass spectrometry. Mass Spectrom. Rev. 23, 368-389.

43. Maier, C. S. \& Deinzer, M. L. (2005). Protein conformations, interactions, and H/D exchange. Methods Enzymol. 402, 312-360.

44. Cravello, L., Lascoux, D. \& Forest, E. (2003). Use of different proteases working in acidic conditions to improve sequence coverage and resolution in hydrogen/deuterium exchange of large proteins. Rapid Commun. Mass Spectrom. 17, 2387-2393.

45. Resing, K. A. \& Ahn, N. G. (1998). Deuterium exchange mass spectrometry as a probe of protein kinase activation. Analysis of wild type and constitutively active mutants of MAP kinase kinase-1. Biochemistry, $37,463-475$.

46. Halgand, F., Dumas, R., Biou, V., Andrieu, J. P., Thomazeau, K., Gagnon, J. et al. (1999). Characterization of the conformational changes of acetohydroxy acid isomeroreductase induced by the binding of $\mathrm{Mg}^{2+}$ ions, NADPH, and a competitive inhibitor. Biochemistry, 38, 6025-6034.

47. Engen, J. R., Smithgall, T. E., Gmeiner, W. H. \& Smith, D. L. (1999). Comparison of $\mathrm{SH} 3$ and $\mathrm{SH} 2$ domain dynamics when expressed alone or in an $\mathrm{SH}(3+2)$ construct: the role of protein dynamics in functional regulation. J. Mol. Biol. 287, 645-656.

48. Freund, C., Gehrig, P., Holak, T. A. \& Pluckthun, A. (1997). Comparison of the amide proton exchange behavior of the rapidly formed folding intermediate and the native state of an antibody $\mathrm{ScFv}$ fragment. FEBS Lett. 407, 42-46.
49. Deng, Y. \& Smith, D. L. (1999). Rate and equilibrium constants for protein unfolding and refolding determined by hydrogen exchange-mass spectrometry. Anal. Biochem. 276, 150-160.

50. Mandell, J. G., Falick, A. M. \& Komives, E. A. (1998). Measurement of amide hydrogen exchange by MALDI-TOF mass spectrometry. Anal. Chem. 70, 3987-3995.

51. Figueroa, I. D. \& Russell, D. H. (1999). Matrix-assisted laser desorption ionization hydrogen/deuterium exchange studies to probe peptide conformational changes. J. Am. Soc. Mass Spectrom. 10, 719-731.

52. Andersen, M. D., Shaffer, J., Jennings, P. A. \& Adams, J. A. (2001). Structural characterization of protein kinase $\mathrm{A}$ as a function of nucleotide binding. Hydrogendeuterium exchange studies using matrix-assisted laser desorption ionization-time of flight mass spectrometry detection. J. Biol. Chem. 276, 14204-14211.

53. Mandell, J. G., Baerga-Ortiz, A., Akashi, S., Takio, K. \& Komives, E. A. (2001). Solvent accessibility of the thrombin-thrombomodulin interface. J. Mol. Biol. 306, 575-589.

54. Mandell, J. G., Baerga-Ortiz, A., Falick, A. M. \& Komives, E. A. (2005). Measurement of solvent accessibility at protein-protein interfaces. Methods Mol. Biol. 305, 65-80.

55. Reed, R. B., Sandberg, M., Jahnsen, T., Lohmann, S. M., Francis, S. H. \& Corbin, J. D. (1996). Fast and slow cyclic nucleotide-dissociation sites in cAMPdependent protein kinase are transposed in type Ibeta cGMP-dependent protein kinase. J. Biol. Chem. 271, 17570-17575

56. Pinkse, M. W., Heck, A. J., Rumpel, K. \& Pullen, F. (2004). Probing noncovalent protein-ligand interactions of the cGMP-dependent protein kinase using electrospray ionization time of flight mass spectrometry. J. Am. Soc. Mass Spectrom. 15, 1392-1399.

57. Scholten, A., Fuss, H., Heck, A. J. \& Dostmann, W. R. (2007). The hinge region operates as a stability switch in cGMP-dependent protein kinase Ialpha. FEBS J. 274, 2274-2286.

58. Wyttenbach, T. \& Bowers, M. T. (2007). Intermolecular interaction in biomolecular systems examined by mass spectrometry. Annu. Rev. Phys. Chem. 58, 511-533.

59. Valentine, S. J., Liu, X., Plasencia, M. D., Hilderbrand, A. E., Kurulugama, R. T., Koeniger, S. L. \& Clemmer, D. E. (2005). Developing liquid chromatography ion mobility mass spectrometry techniques. Expert Rev. Proteomics, 2, 553-565.

60. Ruotolo, B. T., Giles, K., Campuzano, I., Sandercock, A. M., Bateman, R. H. \& Robinson, C. V. (2005). Evidence for macromolecular protein rings in the absence of bulk water. Science, 310, 1658-1661.

61. Sharon, M. \& Robinson, C. V. (2007). The role of mass spectrometry in structure elucidation of dynamic protein complexes. Annu. Rev. Biochem. 76, 167-193.

62. Yuasa, K., Michibata, H., Omori, K. \& Yanaka, M. (2000). Identification of a conserved residue responsible for the autoinhibition of cGMP-dependent protein kinase Ia and Ib. FEBS Lett. 466, 175-178.

63. Heil, W. G., Landgraf, W. \& Hofmann, F. (1987). A catalytically active fragment of cGMP-dependent protein kinase. Occupation of its cGMP-binding sites does not affect its phosphotransferase activity. Eur. J. Biochem. 168, 117-121.

64. Kim, C., Cheng, C. Y., Saldanha, S. A. \& Taylor, S. S. (2007). PKA-i holoenzyme structure reveals a mechanism for cAMP-dependent activation. Cell, 130, 1032-1043. 
65. Chestukhin, A., Litovchick, L., Schourov, D., Cox, S. Taylor, S. S. \& Shaltiel, S. (1996). Functional malleability of the carboxyl-terminal tail in protein kinase A. J. Biol. Chem. 271, 10175-10182.

66. Dostmann, W. R., Koep, N. \& Endres, R. (1996) The catalytic domain of the cGMP-dependent protein kinase Ialpha modulates the cGMP-binding characteristics of its regulatory domain. FEBS Lett. 398, 206-210

67. Cheng, X., Ma, Y., Moore, M., Hemmings, B. A. \& Taylor, S. S. (1998). Phosphorylation and activation of cAMP-dependent protein kinase by phosphoinositide-dependent protein kinase. Proc. Natl Acad. Sci. USA, 95, 9849-9854.

68. Moore, M. J., Kanter, J. R., Jones, K. C. \& Taylor, S. S. (2002). Phosphorylation of the catalytic subunit of protein kinase A. Autophosphorylation versus phosphorylation by phosphoinositide-dependent kinase-1. J. Biol. Chem. 277, 47878-47884.

69. Sastri, M., Barraclough, D. M., Carmichael, P. T. \& Taylor, S. S. (2005). A-kinase-interacting protein localizes protein kinase A in the nucleus. Proc. Natl Acad. Sci. USA, 102, 349-354.

70. Durocher, Y., Perret, S. \& Kamen, A. (2002). Highlevel and high-throughput recombinant protein production by transient transfection of suspensiongrowing human 293-EBNA1 cells. Nucleic Acids Res. 30, E9.

71. Dostmann, W. R., Nickl, C., Thiel, S., Tsigelny, I., Frank, R. \& Tegge, W. J. (1999). Delineation of selective cyclic GMP-dependent protein kinase Ialpha substrate and inhibitor peptides based on combinatorial peptide libraries on paper. Pharmacol. Ther. 82, 373-387.

72. Connelly, G. P., Bai, Y., Jeng, M. F. \& Englander, S. W. (1993). Isotope effects in peptide group hydrogen exchange. Proteins: Struct. Funct. Genet. 17, 87-92.

73. Giles, K., Pringle, S. D., Worthington, K. R., Little, D., Wildgoose, J. L. \& Bateman, R. H. (2004). Applications of a travelling wave-based radio-frequency-only stacked ring ion guide. Rapid Commun. Mass Spectrom. 18, 2401-2414. 